\title{
The Role of Using English Newspapers in Enhancing Pre-intermediate Level Learners' Reading Comprehension Skills
}

\author{
Ranwa Khorsheed \\ Damascus University, Syria; \\ Arab International University, Syria \\ Joumana Rassoul \\ Damascus University, Syria; \\ Arab International University, Syria
}

\begin{abstract}
Several newspaper based reading comprehension sessions for pre-intermediate learners were conducted at the foreign languages center at Arab International University. Using newspapers was a first in remedial English courses at the FLC. The learners were excited to explore newspapers with their different sections. They were required to apply their reading comprehension skills while attempting to read a newspaper article: skimming, scanning and summarizing. The learners ability to cut through the challenging task was measured by a written assessment as they were required to present a summary of the main ideas of a chosen article in addition to expressing their own personal opinion. The learners were judged according to four points: the linguistic structure, dependence on the original text, the number of ideas presented, and expressing their personal opinion. Finally, the learners' feedback on the current experience was collected via a questionnaire.
\end{abstract}

Index Terms — newspapers, reading comprehension, pre-intermediate, skimming, scanning, summarizing

\section{INTRODUCTION}

Most language classes or courses depend on standardized Language text books. Using these books might enforce certain teaching techniques by the language instructor. Besides, a dull traditional learning atmosphere is more likely to dominate the language classroom. Thus, introducing a new and contemporary teaching tool into the classroom would have a great effect on student's interaction and involvement.

The importance of newspapers:

Newspapers are an important form of mass media which plays a vital role in every individual's life (Bucura \& Posa, 2011). In addition to being a source of pleasure for its readers, newspapers can be considered as the basic prototype of today's modern socialization tools. Newspapers connect individuals to their local society and other foreign societies as well. Furthermore, newspapers are looked at as vehicles of literacy that deliver knowledge to all individuals matching all differences of education, age, social class and other interests. Some would think of newspapers as a true documentation of nations' history as they offer vivid snapshots of different aspects of a societal life whether economic, social, religious, educational or political (Bankole \& Babalola, 2011; Babalola,2002; and Schoenback, 2005).

Newspapers as a teaching tool:

Many instructors and educators have incorporated the use of newspapers as an effective learning tool whether in the language classroom or in other subjects since they are up to date and can easily replace the old typical outdated learning textbooks (Bucura \& Posa, 2011; and Sanderson, 1999). Newspapers seem to be an attractive teaching tool that links learners to reality. This is especially noted in the language classrooms that were accustomed to using regular textbooks that are probably fabricated and tailored in a way that is far from real life incidents. Newspapers grant students the chance to deal with real English in addition to experiencing natural reactions due to reading real life events and incidents. This experience is priceless for language learners as they get to tackle real English and get in touch with an immediate source that reflects the foreign culture which normally accompanies the target language. In addition, It has been proved that newspapers enhance readership, enrich learners' vocabulary, improve their writing skills, cultivate critical thinking, clarify cultural values, broaden readers' perspectives and strengthen real life decision making and problem solving skills (Bankole \& Babalola,2011; El-Madwi, 2014;and Brown,1989). Furthermore, reading newspapers would definitely give rise to and elevate students' sense of linguistic achievement in addition to boosting their confidence and motivation.

Linguistic skills taught by newspapers:

Newspapers use can be adapted to fit the teaching of many linguistic skills. These skills can be taught collectively in a simple newspaper based task. On the other hand, each linguistic skill can be taught individually using specifically 
tailored newspapers based activities. These skills can be classified into four basic linguistic skills along with other complementary ones with a little addition and refinement.

Speaking and communication skills:

Reading newspapers aloud in the classroom would contribute to and enhance learners' phonemic awareness, fluency and enrich their vocabulary bank (Bernadowski, 2011). Students can be guided to act out specific role plays based on newspapers texts (Bucura \& Posa, 2011; Chandler, 1988; Daly, 2004; Hess, 1987; Mehta, 2010; and Sanderson, 1999). As for improving learners' fluency, this can be noted after holding several group and pair discussions on different newspaper articles in a number of sessions. Students will learn to express their opinion and activate their critical thinking skills (Babalola, 2002; Bankole \& Babalola, 2011; Elmadwi, 2014; Riaz, 2012; and Worthy.. etal, 2002).

Studying skills:

Dealing with newspapers would help learners acquire useful studying skills. When confronting a newspaper, students would resort to several techniques to facilitate the comprehension process. Thus, students would learn how to do brain storming, take notes, organize ideas, summarize important information and use abbreviations in their notes (Riaz, 2012; and Ping, 2011).

Reading skills:

Language learners can earn a lot of benefits from newspapers, especially when it comes to their reading skills. Learners would be taught two techniques: skimming and scanning. These techniques would enable them to identify the general idea and main details of an article within a minimum of time (Cheyney, 1992; and Riaz, 2012). Furthermore, learners would be introduced to two forms (styles) of reading: intensive and extensive reading. In intensive reading, learners would tackle articles closely and become aware of text organization, justify the use of certain context based expressions and get acquainted with different writing styles used in different types of articles (Echevarria ...etal, 2008; and Elmadwi, 2014). It is worth adding that intensive reading sometimes requires handling difficult readings which might usually exceeds the learners' level of comprehension. However, such practice would normally be considered a boost to the learners' abilities (Aiex, 2000; Brown...etal, 1989; Elmadwi, 2014; and Riaz, 2012). On the other hand, extensive reading would allow learners to practice reading on a daily basis and thus get familiar with a good number of topics and articles classified under different genres (Antepara, 2003; Elmadwi, 2014; and Riaz, 2012).

\section{Writing skills:}

Reading newspapers would help learners pick up different structures and vocabulary, and implement them in their writings. In addition, learners would be familiarized with different writing styles and techniques when reading different sections of newspapers that are written differently since each section serves a distinguished purpose (Riaz,2012). Newspapers headlines and photos can be used as intriguing elements that motivate learners to write their own version of the original story. Learners could even attempt writing a letter to the editor addressing a certain problem or select a job add and write a cover letter (Brown,1989).

\section{Current research aim and importance:}

This research paper aims at introducing newspapers as a teaching tool to pre-intermediate level English language learners. Newspapers will mainly be used to enhance students' comprehension skills and to introduce them to real English. In addition, students would be familiarized with a new genre of English and they would note the similarities and differences between text books' language and the language of newspapers. Furthermore, students' engagement with newspapers would help them develop steady reading habits that will definitely be fruitful on the long run. It is worth adding that reading newspapers,along with the exercises designed by the researcher, would improve students' skimming, summarizing, paraphrasing and writing skills.

\section{Rationale of research:}

One aspect that distinguishes students registered at the FLC, is that most of them are obliged to take remedial English courses in order to proceed with the specialized courses related to their majors. Thus, it was observed that these learners lack the interest and motivation to learn English and develop their skills, especially their reading skills being bored with the traditional outdated topics discussed in their language text books. Eventually, some tutors at the FLC suggested holding reading comprehension sessions based on newspapers' topics, hoping that this would affect students' general attitude towards the English courses and increase their interest, motivation to learn the language, and enhance their linguistic achievement.

\section{Methodology}

\section{Participants:}

The chosen participants will be a group of 20 pre-intermediate (level one) learners of English who are registered students at the foreign language center at Arab International University. The students belong to the (18-20) age group.

\section{Research context:}

The current research has taken place at the foreign languages center (FLC) at the Arab International University (a private Syrian university). The FLC is a language center that offers remedial English courses to students enrolled at the AIU. These courses are mainly divided into four levels $(0,1,2,3)$. In addition, the center offers special courses for academic writing \& research, communication skills, and Toefl preparation courses. It is also worth noting that there are other courses for European languages e.g. German, French and Spanish. As for the nature of the English remedial 
courses held at the FLC, they could be described as typical language courses that teach the four basic linguistic skills (Listening, reading, writing, and speaking) using regular Language learning text books. With regard to using unconventional teaching materials in the English courses, it should be clarified that no such materials have been used especially newspapers which are the object of concern. Teachers at the FLC only use the course books and their packs of software assigned by the management.

\section{Procedures and instruments:}

The researchers have scheduled three one-hour sessions to apply the research and assess its outcomes. The researchers used a dozen of an English newspaper edition (The Daily Star) in the reading sessions.

\section{The first session: Introducing newspapers}

In the first session, the researchers brought a dozen of the English newspaper (The Daily Star) and distributed a copy to each pair of learners. First, the learners were asked to examine the number of pages of the whole paper, the lengths and shapes of articles, the fonts and the photos. Then, learners were guided through the different sections of the paper with a thorough explanation of the function of each section (stories, letters, reviews, letters to editor, puzzles, weather grids, sports, advice columns, Ads, editorials, horoscopes...etc.).

\section{The second session: preliminary training for using the newspaper}

In the second session, the researchers chose an article from the newspaper to discuss with the learners and examine its structure and features. The article was entitled (The Human Hen), which talks about the strange experiences of an unusual artist. The article was chosen based on the learners' interest in artistic topics since most of them were majoring in Arts and Architecture. In addition, the language of the article was relatively simple taking in to consideration the fact that it is the learners' first attempt to read a news article. First, learners' attention was drawn to the title and the overall structure of the article and how it differs from the typical structure used in their language learning text books e.g. the use of the inverted commas, passive voice, inter sentence coordination, inter paragraph coordination, appositive noun phrases and participle phrases. The researchers also pointed out the use of the telegraphic style in the article. Then, the learners were asked to examine the photo accompanying the article and to check if it conveys the message. After that, the learners were asked to read the article silently and choose one of four statements written on the white board that best summarize the article. Next, the learners had to underline the topic sentence in each paragraph, mark the supporting sentences, and highlight the key words. By doing these steps, the learners were applying the skimming technique they normally used in their regular reading sessions. The learners were also guided to look for specific details like dates, numbers, names, and places mentioned in the article. The latter step is considered as an application for the scanning technique. The learners were also asked to identify what is usual (typical) art and artist and compare it to the kind of art and artist presented in the article. This task helped students draw connections between the article and the real world and prior knowledge which is considered as an application of the schema theory and the think aloud technique.

\section{The third session: Assessment}

In the third session, each group of two students had to choose an article from the newspaper, read it, use scanning and skimming techniques, and present a written summary. This was the assessment process along with a questionnaire distributed to gather the learners' evaluation of this learning experience. Further details on the procession and results of the questionnaire and this session would be provided in the results discussion section.

\section{RESULTS AND ANALYSIS}

\section{Research results:}

It was noted that the majority of the learners (99\%) have chosen the same article which was an advantageous point that facilitated evaluating and assessing their degree of comprehension. The chosen article was a sports article about the famous tennis player Rafael Nadal. Consequently, ten summaries were submitted by ten pair groups. The summaries were evaluated according to the following points: the linguistic structure, dependence on the original text, expressing personal opinion and presenting all the main ideas of the article. These points would be further explained in the coming sections.

\section{Linguistic structure:}

Only two of the ten pair groups have submitted summaries using their own language to present the main ideas without quoting or borrowing expressions or clauses from the original text. These two summaries have displayed a very good use of grammar in complete sentences and a variety of vocabulary. The following are examples taken from the groups' summaries:

a. "Monte Carlo has been an important event in Nadal's life"

b. " He surrendered his No.1 ranking after losing to Djokovic"

\section{Dependence on the original text:}

Two of the groups submitted summaries in which they partially used their own language and partially used some sentences extracted from the original text e.g.

a. "He improved and won again many titles"

b. "He had a tough start to the season when he first played in 2003" 
On the other hand, four groups submitted summaries with complete sentences literally extracted from the original text like using the first line or the topic sentence of each paragraph to present its main idea. Two of these summaries have used the title and the subtitle amongst the main ideas while other ideas were presented in run on sentences e.g.

a. "The son of Spain, 30 years old Rafael Nadal breaks the record of Monte Carlo title with ten successful victories."

The last two groups submitted two summaries in which they partially used a telegraphic language similar to that of the title. They also inserted additional outside information about Nadal's place of birth, nick name, other winnings, and the reasons for winning. This has reflected the learners' familiarity with the topic and their successful attempt in using their back ground information e.g.

a. "He won 14 times in grand peace for men and 9 times in open France championship"

b. "He is a famous player because of his awards."

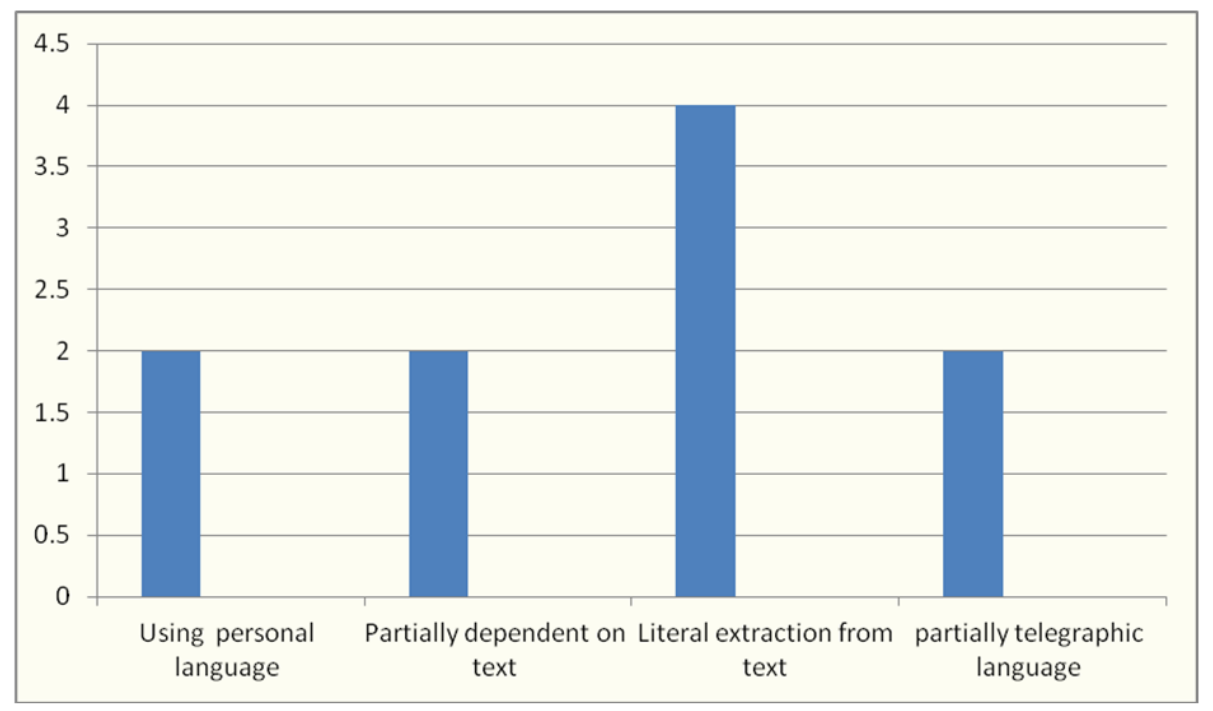

\section{Expressing personal opinion:}

All groups have managed to present their personal opinion at the end of their summaries . All personal opinions were presented using the learners' own language in complete correct sentences e.g.

a. "I think he is the heart of tennis, without him tennis wouldn't be as lively as it is."

However, four of the summaries expressed their hopes for a good future for the tennis player rather than expressing their personal opinion e.g.

a. "I hope Rafa does not quit the game, because he is good at tennis and he is my best player."

Another two summaries did not express their opinion too. But, they rather explained the reasons behind the player's success e.g.

a. "He succeeded in this game because he love it since he was a kid."

\section{Number of ideas presented:}

The article consists of 12 segments (paragraphs). Each paragraph presents a point in Nadal's life or one of his achievements. However, the last four paragraphs mainly focused on his rivalry with another famous tennis player (Ramos). When examining the learners' summaries, it was found out that six summaries have covered 8 of the main ideas presented in the article. On the other hand, the other four summaries have presented only 3 of the main ideas. It is worth mentioning that all of the ten summaries have overlooked presenting the main ideas of the last four paragraphs in the article that discussed the rivalry between Nadal and Ramos.

\section{Learners' feedback questionnaire:}

After finalizing the newspaper based reading comprehension sessions, a questionnaire was distributed to collect learners' feedback and evaluation of this learning experience. The questionnaire mainly consisted of 8 items. After calculating the percentages of the questionnaire, the following results were obtained: About $70 \%$ of the learners liked the variety of the sections and the topics presented in the newspaper more than those discussed in their language learning text books. $80 \%$ of the learners have stated that the language used in newspapers articles is different from the one used in the text books. $40 \%$ of the learners have stated that reading newspapers is easier than reading the texts in their language learning books. $70 \%$ of the learners agreed that the stories in the newspaper are closer to reality than those in their text books. $60 \%$ of the learners have stated that the vocabulary used in newspapers in mostly familiar. When the learners were asked about their most preferable sections of the newspaper, the majority $(80 \%)$ preferred the sports and the art sections.

In class observations:

Further notes were obtained from in class observations during the newspapers reading comprehension sessions. When first introducing newspapers to the learners in the first session, the learners exhibited a high interest and 
excitement to explore their copies of the newspaper. This could be justified by the fact that these learners have never handled an English newspaper before. The size of the paper, the length of the articles, the font size, the titles, the photos, and the different sections, all were elements that attracted and excited the learners. It was also noted that the learners were excited to see, feel and try real English embodied in newspapers articles. At first, the learners found it challenging to read the newspaper article and comprehend its segments. Eventually, with the aid of pair work and the guidance of their instructor, the learners managed to cut through the challenging task.

\section{DISCUSSION AND CONCLUSIONS}

After analyzing learners' summaries, it could be said that most of the learners (65\%) were able to fully comprehend the article and identify its main ideas. Only $20 \%$ of the leaners have displayed an ability to use their own language in complete and correct grammatical structures to present the main ideas. On the other hand, $90 \%$ of the learners were able to express their opinions using complete and grammatically correct sentences. This could hint out to learners ability of self-expression being stimulated by an external factor which is in this case the newspaper article. As for the learners' evaluation of this learning experience, many deductions were made after analyzing the results of the distributed questionnaire. First, it was deduced that the learners liked the variety of the newspaper topics and acknowledged their validity as true stories that occurred in different countries and different contexts. In addition, the learners realized the differences between the linguistic style used in their text books and that of the newspapers. On the other hand, the learners found the vocabulary used in the article familiar to some extent.

\section{Conclusion:}

Conducting this research has proven the possibility of evaluating learners' reading comprehension skills by using newspapers articles. The use of newspapers has challenged the learners' linguistic level as they are accustomed to language learning textbooks with their typical linguistic style. Using newspapers articles, which could be defined as genre based articles, has been a scaffolding process that necessitated taking the learners out of their linguistic comfort zone. In the end, the learners were up to the challenge and managed to adapt to this new learning experience and present satisfactory results. Therefore, it would be highly recommended to use newspapers articles in reading comprehension sessions as an essential part of the remedial English courses at the FLC at the AIU.

Research limitations and recommendations:

The current research has only studied the effects of using newspapers articles on a single group of learners at level one. More comprehensive results would have been obtained if this research was conducted on learners in other different levels. It is recommended to apply the same research using newspapers as a teaching tool to enhance other linguistic skills such as speaking and presenting. In addition, if this research was applied to learners in multiple levels, it would highly be recommended to observe, follow and compare the differences in the learners' linguistic achievements and abilities amongst different levels.

\section{APPENDIX. LEARNERS' FEEDBACK QUESTIONNAIRE}

Name:

\begin{tabular}{|l|l|l|l|}
\hline & Agree & Neutral & Disagree \\
\hline Newspapers are interesting. & & & \\
\hline $\begin{array}{l}\text { I like the topics in the newspapers more than } \\
\text { the topics in my English text book. }\end{array}$ & & & \\
\hline $\begin{array}{l}\text { The language of newspapers is different than } \\
\text { the language of my English textbook. }\end{array}$ & & & \\
\hline $\begin{array}{l}\text { Reading newspapers is easier than reading } \\
\text { The texts in my English text book. }\end{array}$ & & & \\
\hline $\begin{array}{l}\text { The stories in newspapers are more real than } \\
\text { the stories in my English text book. }\end{array}$ & & & \\
\hline The vocabulary in newspapers is all familiar. & & & \\
\hline I like the variety of sections in the newspaper & & & \\
\hline
\end{tabular}

\begin{tabular}{|l|l|l|l|l|l|}
\hline I prefer & Art section & Sport section & Social section & Political & Economic \\
\hline
\end{tabular}

\section{REFERENCES}

[1] Aiex, N.K. (2000). Newspapers as a teaching and communication resource. Online ESL article. ERIC clearing house on reading English and communication. Bloomington. IN.

[2] Antepara, R. (2003). Using news stories in the ESL classroom. The internet TESL Journal, 9 (12). 123-144.

[3] Babalola, E.A. (2002). Newspapers as instruments for building literate communities: The Nigerian experience. Nordic journal of African studies 11 (3), 403-410.

[4] Bankole, O.M and Babalola, S.O. (2011). Use of newspapers by students of Olabisi Onabanjo University, Ago-Iwoye, Ogun State, Nigeria. Library of philosophy and practice (e-journal). Vol. 1, No 1. Paper 462. University of Nebraska- Lincoln.

[5] Bernadowski, C. (2011). A good read, literacy strategies with newspapers. (Newspaper association of America) foundation. 
Senior vice president and secretary/treasurer: Margaret Vassilikos. Arlington.

[6] Brown, A.L., \& Palincsar, A.S. (1981). A guided cooperative learning and individual knowledge acquisition. In L. Resnick (Ed.), Knowing, learning and instruction: Essays in honor of Robert Glaser.

[7] Chandler, C.E. (1988). "Use the news: press to read: Literacy now!", Journal of reading, 31 (8), 746-748.

[8] Cheyney, A.B. (1992). Teaching reading skills through the newspaper. Newark: International Reading Association.

[9] Daly, B. (2004). Facilitating discussions of newspaper articles in the ESL/EFL classroom. The internet TESL Journal, $\mathrm{x}$ (7).232-252.

[10] Echevarria, J., Vogt,M., Short,D.J. (2008). Making content comprehensible for English learners: The Stop model (3rd ed). Boston, MA. Pearson

[11] Elmadwi, M.H. (2014). A study of the significance of using newspapers as an instrument to develop reading and comprehension skills for learning of English as a second language. International Journal of English language, literature and humanities. Vol. 1, No5. 560-580.

[12] Grundy, P. (1994). Newspapers. Issues in applied linguistics. University of California, Los Angeles.

[13] Hess, N. (1987). Newspapers in the English classroom: Stressing sociolinguistic communicative competence in an authentic frame work. English teachers' Journal, 35, 70- 71.

[14] Kenji, K. (1995). "Teaching English through newspapers". English literacy society of Doshisha University.

[15] Kim, I. (2005). The headlines and sentence structure in English language newspapers. Educational research. USA.

[16] Mehata, N.K. (2010). English newspapers: Exploring innovative methodological paradigm. A study into classroom dynamics. Romanian Journal of education. Vol.1, No 1, pp. 55-60.

[17] Ping, W. (2011). Exploring innovative activities in using news stories to teach advanced Chinese learners English in a multimedia way. Journal of English and Literature. 2(5), P 103-122.

[18] Riaz, M. (2013). Task based language learning in English for specific purposes: An exploration in to the use of newspapers for teaching English as a second language to engineering students in Pakistan. The journal of teaching English for specific and academic purposes. Vol. 2, No 4, pp.685-696.

[19] Sanderson, P. (1999). "Using Newspapers in the Classroom”. Cambridge University Press, United Kingdom.

[20] Schoenbach, K. (2005). Newspapers and their impact on the extent of the perceived public agenda. European Journal of communication. 20, 2, 245, - 258.

[21] Tafani, V. (2009). Teaching English through Mass Media. Acta Didactica Napocensia. 2 (1), P 84-111.

[22] Worthy, J. \& Broaddus, K. (2002). Fluency beyond the primary grade: from group performance to silent independent reading. The reading teacher, 55 (4), 334-43.

Ranwa Khorsheed, born in Damascus, Syria, June, 1984. Studied English language and literature at Damascus University. Got a Master degree in general linguistics, Damascus University, 2014.

She worked for private language institutes. Also worked as an English language instructor at Damascus University. (2015-Present) working for the Syrian Virtual University and the Arab international University in Damascus, Syria.

Joumana Rassoul, born in Damascus, Syria, May, 1987. Studied English language and literature at Damascus University and graduated in 2009.

She worked for Elementary schools in Damascus, Syria. (2016-present) working for the Arab international University in Damascus, Syria. 